\title{
TANITMA: Bilgin Güngör, Postkolonyalizm ve Edebiyat: Türk Edebiyatında Sömürgeciliğe Baksş, Hece, Ankara, 2018, 359 s.
}

Kaan YALNIZ1

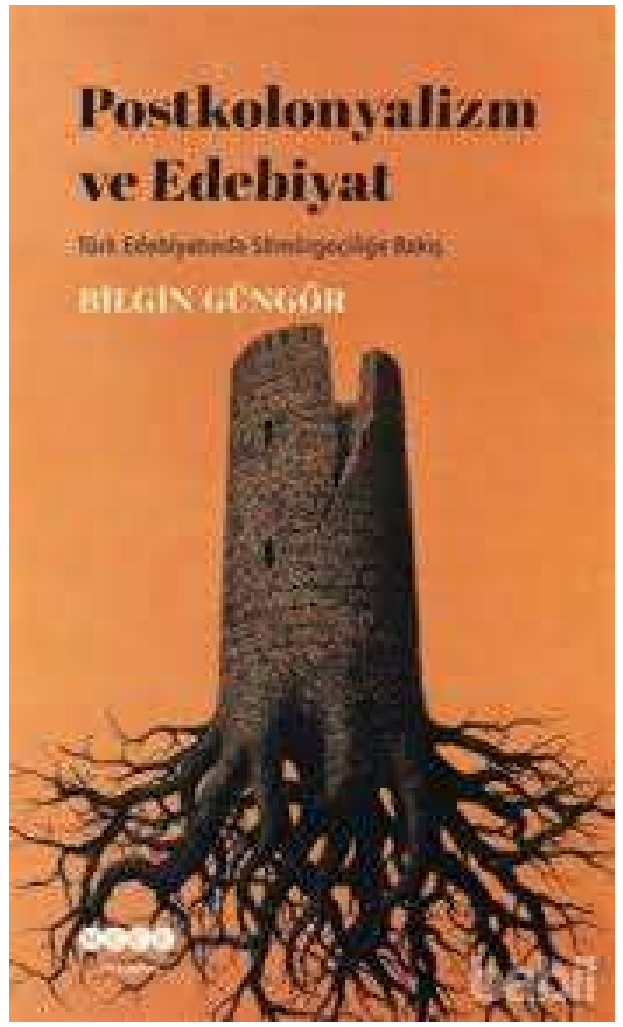

Postkolonyal edebiyat eleştirisi, bir metot olarak kolonyalist Batı ülkelerindeki ve kolonyal süreçlere tabi olan üçüncü dünya ülkelerindeki edebiyatları kolonyalizm ve ilgili olgular çerçevesinde ele almaya dayanan, tek eleştiri ekolü olarak dikkat çeker. Postkolonyal edebiyat eleştirisi, edebî metinlerde konu/tema ve söylem olarak karşımıza çıan kolonyal süreçlerin ve ilgili olguların açılanması, incelenmesi ve değerlendirilmesi esasına dayanır. Türkiye'nin kolonyal süreçlere öncülük etmemiş ve maruz kalmamış bir ülke olması neticesinde postkolonyal çalışmalardan muaf tutulmasını, postkolonyal çalışmalardaki kuramsal perspektifin ve bakış açısının zayıf bir noktasına işaret ettiğini savunan Bilgin Güngör bu noktada kolonyal süreçlere etken veya edilgen bir şekilde dahil olmamış ülkelerin postkolonyal çalışmalarda göz önünde bulundurulmasının gerekliliğine vurgu yaparak çalışmasını bu temel üzerine bina eder. Yoğun bir çalışma ve emeğin ürünü olduğu anlaşılan Bilgin Güngör'ün "Postkolonyalizm ve Edebiyat: Türk Edebiyatında Sömürgeciliğe Bakış” adlı bu kitabı, postkolonyal edebiyat eleştirisi özelinde söz konusu kuramsal zeminin yeniden düşünülmesi noktasında ve modern Türk edebiyatında kolonyal süreçlerin yansımalarını tarihsel olarak ortaya koyması bağlamında Türk edebiyatı özelinde postkolonyalizm ve edebiyat ilişkisine özgün bir bakış açısı getirdiğini ve bu durumun neticesinde büyük bir boşluğu doldurduğunu belirtmek gerekir.

Kitap başlıca iki bölüme ayrılır, ilk bölüm olan "Giriş” bölümü kitabın kuramsal düzlemini oluşturur. İlk bölümde "Sömürgecilik", "kolonyalizm" ve kolonyalizm ile ilgili konular ele alınıp tartışlır. Bu başlık altında kolonyalizmin kavramsal açlımına ve tarihsel gelişimine yönelik genel açıklamalar vardır. "Doğu ülkelerindeki ucuz işgücü ile hammaddeyi asker gücüyle oluşturulmuş koloniler aracıllğıyla doğrudan sömürmesine o ülkeleri yönetmesine dayalı bir sistem" olan kolonyalizmin iki ayrı dönemi (modern öncesi kolonyalizm dönemi ve modern kolonyalizm dönemi) arasındaki temel farklılıklar ele alınıp incelenirken, kolonyalizmin belli hususiyetleri açllımlanır ve kolonyalizmin tarihsel sürecine dair bilgiler verilir. (s. 12-26.)

"Postkolonyalizm ve Postkolonyal Edebiyat Eleştirisi” adlı bölümde öncelikle postkolonyalizmin ne olduğu üzerinde durulur. Postkolonyalizmin "kolonyalizm çağı sonrası düzenini/dönemini imlemekle birlikte özellikle Frantz Fanon'un Yeryüzünün Lanetleri ile Edward Said’in Şarkiyatçılı adlı kitaplarındaki kolonyalizmin eleştirilerinden kaynağını bulan ve 1980’lerden itibaren sosyal bilimler

1 Dr. Öğrencisi, Marmara Üniversitesi, Türkiyat Araştırmaları Enstitüsü, TDE ABD, Yeni Türk Edebiyatı Bilim Dalı, , (İstanbul, Türkiye), kaanyalnz@gmail.com, ORCID ID: oooo-0003-4854-2717 [Makale kayıt tarihi: 15.03.2019-kabul tarihi: 17.03.2019; DOI: 10.29000/rumelide. 541098] 
alanında ön plana çıkan kuramlar bütünün genel ismidir.” (s. 27) şeklinde genel tanımı yapılır ve postkolonyalizmin ve postkolonyal çalışmaların hedefleri ve temel mantalitesi, belli nitelikleri hakkında bilgiler verilir. "Hem kolonize edilmiş ülkelerin hem de kolonici ülkelerin edebiyatlarında kolonyalizm ve ilgili olgulara dair izler ara[yan]" postkolonyal edebiyat eleştirisi "kolonici Batı medeniyetinin kolonize ettiği ülkelerde bırakmış olduğu etkileri edebî eserlerde ele al[ır], onların özellikle söylemlerine yansıyan kolonyalist izdüşümü araştır[ır.]" (s. 32) Postkolonyal edebiyat eleştirisi bunu yaparken estetik kolonyalist söylem ve estetik antikolonyalist söylem olmak üzere iki türlü söylem ile karşılaştı̆̆ yazar tarafından vurgulanan bir başka bahistir.(s. 34-35)

"Modern Türk Edebiyatını Postkolonyal Edebiyat Eleştirisi Işığında Okumak: Estetik Kolonyalizm Söylemi ile estetik Antikolonyalizm Söylemi Etrafında Türk Edebiyatı” başlı̆̆ altında postkolonyal araştırmaların kolonize eden ve edilen ülkelerin edebî verimleri etrafında sınırlamanın yanlış bir bilimsel yaklaşım olacağı açıklanırken kolonyalizm sürecine ne etken ne de edilgen bir şekilde katılan ülkelerde dahi "kolonyal semptomlar”a rastlamanın mümkün olduğu gerçeği üzerinde durularak Türk edebiyatında da başlangıçtan günümüze birçok edebî eserde kolonyalizm ile ilgili olgulara rastlandığının altı çizilir. Bu eserlerde kolonyalizmin olumsuzlandığı, eserlerde daha çok estetik antikolonyalizm söylemine şahit olunduğu ve kolonyalizm olgusunun rastlanıldığı eserlerin büyük çoğunun şiir türü içerinde bulunduğu ifade edilir. (s. 37)

Kitabın ikinci bölümü ise "Türk Edebiyatında Sömürgeciliğe (Kolonyalizme) Bakış" adını taşır ve Türk edebiyatında kolonyalizm olgusunun yansıma alanı bulduğu eserlerin incelemeye/değerlendirmeye tâbi tutulduğu bölümdür. Bu bölüm kendi arasında yine iki ana bölüme ayrllır ki ilk bölüm Tanzimat’tan Cumhuriyet'e edebî eserlerde, ikinci bölüm ise Cumhuriyet devri edebî eserlerinde kolonyalizm olgusunu konu edinecek şekilde bir sınıflandırmaya gidilir. İlk bölüm "Tanzimat'tan Cumhuriyet'e Türk Edebiyatında Kolonyalizm yahut Efendi-Yazar'la Köle-Okur Arasında (1876-1923)” başlığı taşır. Bu bölümde konuya giriş mahiyetinde Türkiye'nin Batılı anlamda modernleşmesinin temel çizgileri belirtilirken bu Batılılaşmanın edebiyatta yansıma alanı bulması, edebiyatın bu dönemde toplumsal işlevi, kolonyalizmin edebiyatta yer bulmaya başlaması ve Batı karşısında Osmanlı aydınının tavrı gibi konular ele alınır. Dönem sanatçlarının eserlerinde estetik kolonyalizm söylemi ile estetik antikolonyalizm söyleminin bir arada bulunduğunu ifade eden yazar, "Tanzimat'tan Cumhuriyet'e kadarki dönemde edebî eserlere yansıyan kolonyal süreçler ve ilgili olgularla ilgili bahsedilecek en temel nitelik düalizmdir" tespitinde bulunur.(s. 41)

“Tanzimat'tan Cumhuriyet'e Türk Edebiyatında Kolonyalizm yahut Efendi-Yazar'la Köle-Okur Arasında (1876-1923)" başlı̆̆ altında Abdülhak Hâmid, Ahmet Midhat Efendi, Cenap Şahabettin, Mehmet Âkif, Süleyman Nazif gibi şahsiyetlerin eserlerine kolonyal sürecin yansımaları ele alınır ve bu bölümde bahsi geçen her isim birbirinden bağımsız şekilde ayrı ayrı başlıklandırılır.

Abdülhak Hâmid'in "Duhter-i Hindû" adlı eseri Türk edebiyatında ilk defa kolonyalist söylem içeren edebî eser olarak dikkat çeker. Bu eser "Türk edebiyatında estetik antikolonyalizm söylemine kapı aralayan ilk eserdir." (s.45) Kolonyalizm bahsinde değerlendirilen Hâmid'in bir diğer eseri "Finten"dir. Hamid'in piyeslerinde kolonyalizm ile ilgili bahislerin olumsuzlanması, yazar tarafından Hâmid’in Avrupa ülkelerinde sefirlik görevini ifası sırasında "kolonyal sömürünün metropollere yansıyan kısmına bizzat şahit olması" hususuyla ilişkilendirilir.

Ahmet Midhat Efendi ise kolonyalizm ile ilgili konularla ilgilenen bir başka ediptir. Fakat Abdülhak Hâmid'in yaklaşımından farklı olarak Ahmet Midhat estetik antikolonyal söylem çabası içerisine 
girmediği görülür. Batılllaşmanın bir devlet politikası olduğu göz önünde bulundurulursa Midhat Efendi'nin bu yaklaşımının devrin temel ideolojik yönelimiyle yakın bağlantısının olduğuna dikkat çekilir.

Servet-i Fünûn hareketinin önde gelen şahsiyetlerinden olan Cenap Şahabettin'in gezi yazılarında kolonyal süreçlere ve ilgili olgulara yer verildiği ifade edilerek onun gezi eserlerine yansıyan kolonyal süreçlerin Arapların yoğun olarak yaşadığı bölgelerde "Ortadoğu'da İngilizlerin öncülük ettiği kolonizasyon çabalarının ilk dönemlerinde somutlaştığı” tespiti yapılır. (s. 93) Cenap Şahabettin’in müşahede ettiği coğrafyadaki kolonizasyon süreçlerine olan yaklaşımı değerlendirilir.

Kolonyalizm temasını şiirlerinde işleyen bir diğer isim olarak Mehmet Âkif'i görmek mümkündür. Bilgin Güngör, Meşrutiyet yıllarında kolonyalizmi tema olarak işleyerek Batı kolonyalizmini şiirlerinde ele alan başka bir şahsiyetin neredeyse bulunmadığını dile getirerek, onun şiirlerini bu bölümde kolonyalizm düzleminde inceler, Âkif'in "kolonyalizmi Batı medeniyetinin İslâm medeniyetine yönelik tahrip edici etkisi bağlamında" ele aldığı ifade eder. (s.102) Özellikle "Berlin Hatıraları" şiiri Âkifin açık bir şekilde "Şarkiyatçllı" meselesini eleştiri konusu haline getirmesi yönüyle önem teşkil eder. (s. 108)

Süleyman Nazif 1918 yılında yayımladığı Firak-ı Irak adlı şiir kitabındaki "Kübalılar” adlı şiiri Bilgin Güngör tarafından kitapta kolonyalist bağlamda değerlendirilir. Şairin bu şiirinin edebiyatımızda antikolonyalizmin ele alındığı ilk şiir olduğunun da altı çizilerek şairin bu şiirde kolonyalizme reddedici bir tavırla yaklaşması incelemeye konu edilir. Bu şiir İspanyol kolonyalizminden kurtulan Küba'nın antikolonyalist devriminden hareketle kaleme alınmış ve "Endülüs Şühedasına" ithaf edilmiştir.

“Cumhuriyet Dönemi Türk Edebiyatında Kolonyalizm yahut Düalitenin Sonu (1924-2014)” başlıklı bölümde Türk edebiyatındaki kolonyalizm olgusunun genel değerlendirilmesi yapılarak, bu devrin hemen hemen bütün yazar ve şairlerinin Batı karşısında estetik anti-kolonyalist söylem ve antiemperyalist bir tutum içerisinde bulunduğunun altı çizilir. Yazar söz konusu dönemi 1923-1980 ve 19802014 ylları arasında tasnif eder.

“1923-1980 Arasında Türk Edebiyatında Kolonyalizm” başlı̆̆ı altında Cumhuriyet’in ilk elli ylllı dönemi içerisinde şair ve yazarlar tarafından kolonyal süreçler ve ilgili olgular daha önceki dönemlerde hiç olmadığı kadar sorunsallaştı̆̆ı, "transkültürasyon, kültürel melezlik, kültürel çokseslilik, öteki algısı, renk, anti-kolonyalizm gibi olguların" daha geniş ve derin bir perspektifle eserlerde işlendiği yazar tarafından altı çizilen önemli bir bahistir. Bilgin Güngör bu dönemde kolonyalizmin esere aksi bağlamında şiir alanında Nâzım Hikmet, Fazıl Hüsnü Dağlarca ve Sezai Karakoç’un, roman ve hikâye alanında ise "yaklaşı 16 yılını Fransızların o devirde kolonisi olan Suriye coğrafyasında" geçiren Refik Halid Karay’ın öne çıktığını söyler. (s. 115)

Refik Halid Karay'ın Suriye'de geçirdiği sürgün yılları boyunca coğrafyadaki Fransız kolonizasyonunu birebir müşahedesi neticesinde eserlerinde kolonizasyon sürecini ve ilgili olguları aktarmasına değinildikten sonra onun "Sürgün”, "Dişi Örümcek”, "Yer Altında Dünya Var”, "Yezidin Kızı" adlı romanları ile "Gurbet Hikâyeleri”ndeki bazı hikayeleri bu bağlamda incelenir. Falih Rıfkı Atay'ın "Zeytindağı" adlı anı-roman türündeki eseriyle Yahudi kolonyalizmine temas etmesi bakımından kitapta incelenen bir diğer eserdir.

Şiirlerinde kolonyal süreçleri konu edip ele almasından dolayı Nazım Hikmet dönemin önde gelen şairleri arasında yer alır. Anti-kolonyalizm söyleminin yanı sıra onun şiirlerinde içkin olarak "anti- 
emperyalizm miti”nin yer aldığını ifade eden yazar, bu bölümde "Açların Gözbebekleri”, "Korsan Türküsü”, "Piyer Loti”, “Jokond ile Sİ-YA-U”, “Benerci Kendini Niçin Öldürdü?” gibi şiirlerde şairin şiirine yansıyan kolonyalizm sürecini çeşitli yönleriyle inceleyerek okuyucunun dikkatine sunar.

Fazıl Hüsnü Dağlarca bölümünde ise şairin anti-kolonyalist tavrın hâkim olduğu eserlerinin başında “Batı Acısı” ve "Cezayir Türküsü” geldiğini saptaması yapılırken, çă̆daşı diğer şairlerden farklı olarak kolonyal süreçleri "Kemalist ideolojinin oluşturduğu bir duyarlılıkla" yansıttığı belirtilir. Ercümend Behzad Lav da kitapta şiirleri incelenen bir diğer şairdir, onun "Mau Mau" adlı kitabı Afrika özelinde anti-kolonyalizm söylemi bağlamında ele alınır.

Sezai Karakoç Türk edebiyatının geneli düşünüldüğünde eserlerinde kolonyalizmi en çok konu edinen isimlerden biri olduğu belirtilerek, onun kolonyalizm ile ilgili şiirlerindeki ideolojik eğilim ve estetik tavrı daha iyi aydınlatmak adına "İslâmın Dirilişı" ve "Diriliş Neslinin Âmentüsü" adlı kitaplarına başvurularak "Diriliş” kavramına açıklık getirilir. İkinci Yeni şairleri arasında Sezai Karakoç’tan sonra şiirine kolonyalist olguları sokan diğer iki şair, Cemal Süreya ve İlhan Berk'tir. Süreyya Berfe’nin “Sierra Maestra” adlı şiirinde Küba’nın bağımsızlık mücadelesi özelinde incelenirken, Hilmi Yavuz’un "Bakış Kuşu” adlı şiiri İsmet Özel’in "O Bağımsız Dağların”, “Bir Devrimcinin Armonikası” gibi şiirleri yine kolonyalizm ve ilgili olgular bağlamında ele alınır.

Cahit Zarifoğlu şiirlerinde kolonyalizme yoğun şekilde yer verir ki özellikle "Korku ve Yakarış" kitabında emperyalist Batı ve SSCB’nin İslâm dünyasına yönelik tahrip süreçleri yer alırken, o bu şiirlerinde adeta "İslâm dünyasının sözcülüğünü yapar ve mazlum Müslüman halkların acılarına, dramlarına ve içerisinde bulunduğu kargaşa ortamına şiirinin kapılarını tamamen açar." (258) Nuri Pakdil, Erdem Bayazıt, Akif İnan, kitapta bu dönemde şiirleri kolonyalist süreçler açısından değerlendirilen diğer sanatçılar olarak dikkat çeker. Nuri Pakdil'in tematik ve söylemsel açıdan kolonyalizmi barındıran şiirleri “Anneler ve Kudüsler” adlı kitapta toplanmıştır. Erdem Bayazıt’ın şiirlerinde Âkif, Sezai Karakoç, Cahit Zarifoğlu Akif İnan'da olduğu gibi kolonyalizm, "İslam dünyası merkezinde" ele alındığı ifade edilir. (s. 284) Hekimoğlu İsmail ise "Minyeli Abdullah" adlı romanında anti-kolonyalist tutumuyla incelemeye konu olur.

“1980-2014 Arasında Türk Edebiyatında Kolonyalizm” başlı̆̆ı altında kolonyal süreçler ve ilgili olguların bu dönemde Türk edebiyatında daha az yansımalar bulduğu ifade edilirken bu durumun, 12 Eylül sonrası edebiyatta yaşanan postmodern dönüşüm, üçüncü dünyanın büyük oranda bağımsızlığını kazanması ve anti-kolonyalist hareketlerin başarıya ulaşması şeklinde nedenleri olduğu yazar tarafından okuyucunun dikkatine sunulur. (s. 298) Genel anlamda dönemde İsrail'in Filistin topraklarına ve halkına uyguladığı kolonyalist tutumun/hareketin eserlerde yer bulduğunun da yazar tarafindan vurgulanan bir diğer önemli bahistir. Bu bağlamda Cahit Konyak’ın "Gazze Risalesi” adlı eserindeki şiirleri, Sevinç Çokum'un ve Cemal Çakar'ın hikâyeleri, Markar Esayan’ın “Jerusalem” adlı romanı kitapta incelemeye konu olan eserler arasındadır.

Netice itibariyle Bilgin Güngör'ün "Postkolonyalizm ve Edebiyat: Türk Edebiyatında Sömürgeciliğe Bakış” adlı bu çalışmasının en önemli özelliği postkolonyal edebiyat eleştirisinin kuramsal zemininden kaynaklı bir metotla hareket etmesi ve bu metotla hareket ederek Türk edebiyatında eserlere yansıyan kolonyalizm ve ilgili olguların incelemesi noktasında son derece özgün bir çalışma olmasıdır. Çalışmanın bu yönüyle ve Türk edebiyatına kolonyalizm bağlamında getirdiği bakış açısıyla yukarıda da belirttiğimiz üzere alanına olan katkısı, alanındaki önemli bir boşluğu doldurması, eserin değerini artıran bir diğer önemli özelliği olarak dikkat çekmektedir. Kitabın giriş bölümünde kolonyalizm ve ilgili terimlerin iyi 
BOOK REVIEW: Bilgin Güngör, Postkolonyalizm ve Edebiyat: Türk Edebiyatında Sömürgeciliğe Bakış, Hece, Ankara, 2018, p. 359 / K. Yalnız (p. 548-552)

bir şekilde açıklandığı ve yazarın eseri meydana getirmeden evvel alan ile alakalı geniş bir kaynakçaya yönelerek iyi bir okuma yaptığı dikkatlerden kaçmayan bir diğer bahistir. Yazarın Türk edebiyatını kolonyalizm bağlamında ele alıp tasnif etme noktasındaki tespit ve değerlendirmelerinin oldukça yerinde olduğunu söylemekle birlikte yazarın eseri vücuda getirirken ilgili alanın terminolojisinden oldukça etkili bir şekilde yararlandığını da belirtmemek elde değildir. Tüm bu yönleriyle ve konu itibariyle alanındaki çalışmalara kaynaklık edeceğini düşündüğümüz, her anlamda yetkinlik arz eden çalışmasıyla Bilgin Güngör’ün teşekkürü ve övgüyü hak ettiğini söylemek gerekir (ISBN: 978-605-754710-1) 